\title{
nature
}

\section{End chronic kidney disease neglect}

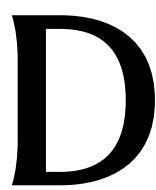

It is unacceptable that kidney-dialysis technology has changed little in the past five decades.

ialysis almost immediately saved lives when it was invented in the first half of the twentieth century to treat kidney disease by safely accessing a patient's blood supply and filtering toxins normally removed by the kidneys.

The original dialysis machine, a rudimentary contraption invented by physician Willem Kolff in the early 1940s, was made from cellophane tubes and a wooden drum. Although today's machines are manufactured industrially, operating technologies have changed little since the 1960s. And that, as we report in a Feature on page 186, is a problem.

The World Health Organization estimates that, each year, around 1.2 million people worldwide die from kidney failure. This is partly a result of the number of people with high blood pressure and diabetes, which strain and damage the kidneys. But a combination of dialysis technology's practical limitations and affordability also means that fewer than half of the people who need treatment can access it.

In Africa, just $16 \%$ of people with kidney disease get dialysis, and even fewer can sustain the cost of treatment for more than a few months. In the United States, where dialysis can cost up to US $\$ 91,000$ per patient per year, fewer than half of those on the most common form of dialysis survive for more than five years from the onset of kidney failure.

A fundamental problem is that dialysis involves connecting patients to machines that can weigh more than 100 kilograms. For most people, that necessitates regular visits to a hospital or dialysis clinic. A typical treatment regime can take 12 hours, spread over 3 weekly sessions that see toxins filtered from the blood and levels of various salts and minerals recalibrated. For patients, this is an ordeal that is both energy-sapping and time-consuming.

Dialysis also consumes resources. Between 120 and 240 litres of filtered water are needed for each 4 -hour session. By one estimate, the annual requirements of the dialysis provided around the world include more than 156 billion litres of water and roughly 1.62 billion kilowatt hours of power - roughly equivalent to the electricity needed to power a small European city for a year. Dialysis also generates some 625,000 tonnes of plastic waste.

Solutions include making dialysis more portable - so that it can be carried out at home or on the move - and finding ways to do it with less water and power. This would be of particular benefit to patients in developing countries.

Promising technologies are being developed to make the machines smaller and more portable. But it is not clear whether these will reach many of those who need them.
Despite the clear need for innovation, research funding is low. Last year, the US government and the American Society of Nephrology announced a plan to raise $\$ 250 \mathrm{mil}-$ lion over 5 years for research. This is welcome, but so far the collaboration, called Kidney X, has disbursed only $\$ 1.1$ million in grants.

The reality is that chronic kidney disease needs the kind of coordinated global effort, involving funders, researchers and patient groups, that some other conditions attract. Together, these groups must support more research into the mechanisms that underlie kidney disease, and approaches to prevent its development and progression.

At the same time, countries could encourage patients' family members to consider kidney donation. On average, transplant patients live longer than do those on dialysis reducing the heavy health and economic burdens of this neglected killer.

\section{DARPA 'lookalikes' must ground their dreams in reality}

\section{The US Defense Advanced Research Projects Agency knows that its freedom to invent comes with responsibility.}

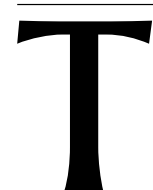

he government of UK Prime Minister BorisJohnson is racing ahead with plans for an Advanced Research Projects Agency (ARPA), modelled on the US original. The country is looking to boost technological competitiveness as it withdraws from the European Union. Precise details of its ARPA plans are yet to be revealed, but the available funding is expected to come to around $£ 800$ million (US $\$ 1$ billion) over 5 years.

The US Defense Advanced Research Projects Agency (DARPA), which supports ambitious technologies for military objectives, was launched in 1958 by president Dwight Eisenhower. The impetus was the Soviet Union's 1957 launch of the first artificial satellite, Sputnik, which demonstrated a level of technological prowess that shocked Western nations. Eisenhower's ambition for DARPA - established in the same year as NASA - was that the US military would never again be left behind in this way.

DARPA's best-known investments include research on the first global satellite-navigation system (known as Transit), stealth aircraft and the Internet's precursor, ARPANET. Today, the many projects funded by the agency include work on developing treatments to regrow severed limbs.

DARPA spends about $\$ 3.5$ billion a year, which is less than $1 \%$ of the total US public and private research and development budget. It's a small enough proportion to justify DARPA's reputation for taking on riskier ideas and having 
a higher tolerance for failure than conventional funding agencies. One idea that famously didn't make it was the hafnium bomb, based on the flawed belief that large amounts of energy can be released by bombarding the isotope hafnium-178 with X-rays.

Although DARPA's research programme managers have relatively more flexibility in what research to fund and how, no country has been able to replicate the scale of the agency's success. Even in the United States its achievements remain unrivalled. A different advanced research projects agency for new energy technologies (ARPA-E) - launched in 2009 - is under constant threat of being eliminated by the administration of President Donald Trump.

One reason why DARPA is so hard to replicate, says DARPA historian Sharon Weinberger, is because the agency's projects have a resource that the others lack. "They have a customer with the deepest pockets in the world," she says. The US Department of Defense's annual budgets for research and procurement, totalling $\$ 190$ billion, enable it to fund successful prototypes on a large scale, to test whether they might be commercially viable.

\section{Risk management}

A closer look at DARPA shows how its managers pursue bold ideas while controlling risk. In a Comment article on page 190, members of a team working with - and in the agency's Biological Technologies Office in Arlington, Virginia, report on an initiative launched in 2016. This assigns an independent validation team to projects to troubleshoot and reproduce research proposals. This 'shadow team' meets with the 'performing team' to learn the precise protocols and establish the necessary conditions to reproduce projects, and the two groups makejoint presentations to the programme manager on progress.

The work is hard - one project took as long as 20 months to reproduce. It is also expensive: it costs between $3 \%$ and $8 \%$ of a programme's funds to make sure the technologies work. But programme managers say it is worth the investment, and the model demonstrates a more careful side to the agency than DARPA's daring image tends to evoke.

These efforts are instructive, both for dreams of a UK ARPA and for science overall. Some of UK ARPA's supporters would like to see cutting-edge technologies developed within 15 years - and a certain ruthlessness when it comes to axing the least promising ones. But an ambitious technology goal in, say, regenerative medicine or remote sensing will probably need longer before careful study can make the promises - and risks - clear.

Researchers, their managers in universities, and funding agencies all understand why effective due diligence is essential to projects. But it can be difficult for these voices to be heard when no less than the prime minister's office celebrates ARPA as "high-risk, high-pay-off research", and characterizes bureaucracy as "form-filling".

Any nation looking to replicate DARPA must realize that you can't reap the rewards of high-risk research without investing in meticulous preparation and verification. The freedom to pursue bold ideas comes with added responsibility.

\section{A lack of locust preparedness}

\author{
Locusts are causing a food crisis that can no \\ longer be ignored.
}

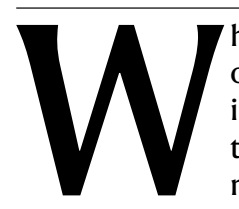

hile all eyes are on the coronavirus outbreak, an under-reported emergency is threatening food, health and jobs on three continents. For the past several months, swarms of the desert locust Schistocerca gregaria - some swarms the size of cities have devoured crops in East Africa, the Middle East and south Asia. Some 20 million people are facing a food crisis.

Governments have been left under-prepared for the scale of these attacks, and the Rome-based United Nations Food and Agriculture Organization (FAO) has appealed for US $\$ 138$ million in urgent funding - some of which is needed to lease aircraft that can drop chemicals to curb the spread.

Locusts are an annual fixture after the rainy seasonlaying their eggs in moist soils. But the size of this year's swarms - the biggest for at least 25 years - are due in part to unseasonal and often torrential rains in many areas, including Eritrea, Ethiopia, Iran, Pakistan, Saudi Arabia and Yemen. The FAO's calls must be heeded - especially as more rains are to come, bringing the potential for yet more devastation. But at the same time, some of the governments concerned must ask themselves what more they could be doing to limit the damage.

In many countries, meteorological offices share climate and weather data with what are called desert-locust-control offices. These are set up to forecast locust infestations, and to advise on potential crop losses and mitigation measures. East Africa has a regional body called the Desert Locust Control Organization for East Africa, headquartered in Addis Ababa and funded by nine African countries.

Nature has been told that some members - such as Djibouti, Somalia and Sudan - have been unable to pay their membership fees for many years and collectively owe the organization more than $\$ 8$ million. Uganda, which partially cleared its arrears last month, still owes $\$ 2$ million. Somalia and Sudan have both experienced severe conflict, so it's understandable that locusts have not been a priority. But the insects can be just as threatening to well-being, and if individual countries can't pay their way, then the African Union or the UN need to step in. Paying into locust-control offices should be regarded as keeping up an insurance policy. The hope with insurance is that it's never needed, but the facility must always be there should the need arise.

The focus now is rightly on emergency food relief. But preparations for coming swarms need to be accelerated. The African Union and the UN must ensure that countries' desert-locust organizations, informed by the latest research, are better equipped to help when the time comes. 